\title{
Weight Fluctuation and Postmenopausal Breast Cancer in the National Health and Nutrition Examination Survey I Epidemiologic Follow-Up Study
}

\author{
Marina Komaroff \\ Department of Epidemiology and Biostatistics, SUNY Downstate Medical Center, Brooklyn, NY 11203, USA \\ Correspondence should be addressed to Marina Komaroff; genmar2k@gmail.com
}

Received 13 October 2015; Revised 10 January 2016; Accepted 12 January 2016

Academic Editor: Francesco Saverio Papadia

Copyright (c) 2016 Marina Komaroff. This is an open access article distributed under the Creative Commons Attribution License, which permits unrestricted use, distribution, and reproduction in any medium, provided the original work is properly cited.

\begin{abstract}
Objective. The aim of this study is to investigate if weight fluctuation is an independent risk factor for postmenopausal breast cancer (PBC) among women who gained weight in adult years. Methods. NHANES I Epidemiologic Follow-Up Study (NHEFS) database was used in the study. Women that were cancers-free at enrollment and diagnosed for the first time with breast cancer at age 50 or greater were considered cases. Controls were chosen from the subset of cancers-free women and matched to cases by years of followup and status of body mass index (BMI) at 25 years of age. Weight fluctuation was measured by the root-mean-square-error (RMSE) from a simple linear regression model for each woman with their body mass index (BMI) regressed on age (started at 25 years) while women with the positive slope from this regression were defined as weight gainers. Data were analyzed using conditional logistic regression models. Results. A total of 158 women were included into the study. The conditional logistic regression adjusted for weight gain demonstrated positive association between weight fluctuation in adult years and postmenopausal breast cancers (odds ratio/OR $=1.67 ; 95 \%$ confidence interval/CI: 1.06-2.66). Conclusions. The data suggested that long-term weight fluctuation was significant risk factor for PBC among women who gained weight in adult years. This finding underscores the importance of maintaining lost weight and avoiding weight fluctuation.
\end{abstract}

\section{Background}

In the United States, one in eight women develops breast cancer after the age of 70 years [1]. Adult weight gain is a modifiable risk factor for postmenopausal breast cancer that can be controlled through diet modification and increased exercise [2-4]. While approximately $40 \%$ of American women attempt to lose weight [5-7], a majority of women do not maintain the lost weight [8-10]. The unsuccessful maintenance of an initial weight loss leads to weight fluctuation, which in turn promotes additional weight gain [11-15].

Each $2 \mathrm{~kg} / \mathrm{m}^{2}$ increase in body mass index (BMI) is associated with $5 \%$ increased risk of postmenopausal breast cancer (Relative Risk/RR $=1.05,95 \%$ CI: 1.03-1.07), 13\% increased risk among overweight women $(\mathrm{BMI}=25-$ $\left.29 \mathrm{~kg} / \mathrm{m}^{2}\right)$, and $25 \%$ among obese women (BMI $\geq 30 \mathrm{~kg} / \mathrm{m}^{2}$ ) $[3,4]$. Little is known or understood about the public health significance of weight fluctuation on the risk of postmenopausal breast cancer.

\section{Introduction}

Currently, postmenopausal breast cancer (PBC) is the most common cancer among women in the United States [1, 1618], but the effect of weight fluctuation as risk factor for $\mathrm{PBC}$ has not been examined enough. Weight fluctuation also known as "yo-yo" dieting is defined as the repeated loss and regain of body weight [19]. Based on evidence from rodent and human studies, the lack of energy during initial caloric restriction induces metabolic efficiencies and fuel conservation that significantly increase tendency to weight gain [7-9, 20-22]. Dieting leads to physiological alterations that favor lipid storage, as well as abdominal accumulation of body fat. In addition, there is an increase in the rate of adipose 
tissue accumulation during weight regain [20-22], which is suggestive of a distinct effect on adipose tissue in the weight fluctuation process. Finally, adipose tissue is a complex and active endocrine and metabolic organ that also influences the synthesis and bioavailability of endogenous reproductive hormones [23-28]. These hormones have been shown to play a primary role in etiology and progression of PBC [23-28]. As a result, because the increase in adipose tissue is a risk factor for development of PBC [23-28], it is hypothesized that weight fluctuation increases the risk of weight gain on the development of PBC.

\section{Materials and Methods}

3.1. Data. Data from NHANES I Epidemiologic Follow-Up Study (NHEFS) includes subjects of 25-74 years of age who completed a medical examination at NHANES I in 19711975 and were followed up in 1982, 1986, 1987, and 1992. The database does not include any private information about participants and is available and open for public use. Methodology of the NHEFS has been described elsewhere [32-36].

3.2. Subjects. The analytic cohort was formed from women enrolled in NHANES I study. They self-reported weight at 25, 40 , and 65 years of age, whereas other weight assessments were a combination of physical exams and questionnaires from the first exam in 1971-1974 through 1992 [32]. Incident cases consisted of women who were initially free of cancers at study entry but were diagnosed for the first time with the PBC during the follow-up years. Controls were selected from the subgroup of cancer-free women at study entry and during the follow-up years and matched to cases by the years of followup, as well as BMI status at 25 years of age defined as underweight $\left(\mathrm{BMI}<18.50 \mathrm{~kg} / \mathrm{m}^{2}\right)$, normal $\left(18.50 \mathrm{~kg} / \mathrm{m}^{2} \leq \mathrm{BMI}<\right.$ $\left.24.99 \mathrm{~kg} / \mathrm{m}^{2}\right)$, overweight $\left(25.00 \mathrm{~kg} / \mathrm{m}^{2} \leq \mathrm{BMI}<30.00 \mathrm{~kg} /\right.$ $\left.\mathrm{m}^{2}\right)$, and obese $\left(\mathrm{BMI} \geq 30.00 \mathrm{~kg} / \mathrm{m}^{2}\right)$ [28]. BMI was calculated using formula weight $(\mathrm{kg}) /[\text { height }(\mathrm{m})]^{2}$, where height was measured during the first physical exam in 1971-1974. Only women who had BMI assessment at age 25 and overall three or more BMI assessments before the postmenopausal breast cancer diagnosis/end of follow-up (for controls) were included into the study. Due to missing values and inconsistencies in collection of age of menopause, the breast cancer diagnosed at age 50 or greater was considered as postmenopausal based on average postmenopausal age among the US women.

3.3. Exclusion Criteria. Women who did not have BMI assessment at age 25 and women with less than three BMI assessments before the postmenopausal breast cancer diagnosis/end of follow-up (for control) were excluded from the study. Lastly, because the major interest in the study is to investigate the association between weight fluctuation and $\mathrm{PBC}$ among women who gained weight in adult years, women with lost weight were also excluded.

3.4. Weight Gain and Weight Fluctuation. Definition of weight fluctuation was based on the results from a simple linear regression model for each woman with her BMI regressed on age. The extent of BMI fluctuation for each participant was estimated with the root-mean-square-error (RMSE) statistic. The subset of women with a positive beta coefficient for age $\left(\beta_{\text {age }}\right)$ from a linear regression models was considered weight gainers and only weight gainers were chosen for the study. Overall, there were 79 cases and 79 controls that satisfied inclusion criteria.

3.5. Data of Other Risk Factors for Breast Cancer. The other postmenopausal breast cancer risk factors were included in the conditional logistic regression as the following covariates: parity or live births $(0,1$, or more), age at the first child greater than 30 (yes/no), history of breast cancer in mother (yes/no), and use of hormone replacement therapy (yes/no).

In 1971-1975, weight and height were measured. In the following years, data were collected on live births, age when first child was born, history of breast cancer in first-degree female relatives (mother), and use of hormone replacement therapy.

3.6. Statistical Analysis. A conditional logistic regression model (PROC LOGISTIC in SAS ${ }^{\circledast}$ ) was developed to assess the increase in risk of $\mathrm{PBC}$ for every unit increase in weight fluctuation measured by root-mean-square-error (RMSE) derived from a simple linear regression for BMI on age (from 25 years). The other risk factors for postmenopausal breast cancer, such as parity, age at the first child greater than 30, history of breast cancer in first-degree female relatives (mother), and use of hormone replacement therapy, were included in the logistic regression model as the covariates.

SAS version 9.2 was used for all analyses where significance tests were two-sided with the level of significance equaling $5 \%$.

\section{Results}

4.1. Demographics and Baseline Characteristics. A total of 79 new cases of breast cancer for women of 50 years of age and older were included in this study and matched to 79 controls by the years of follow-up and BMI status at 25 years of age. The study population was weight gainers and had at least three BMI assessments before the diagnosis/end of follow-up (for controls). Distribution by $50-60,61-70,71-80$, and $>80$ years of age was $51.9 \%, 26.58 \%, 17.72 \%$, and $3.8 \%$, respectively. The mean age at cancer diagnosis was about 63 years (standard deviation $=9.26)$. Most women $(82.28 \%$ ) had normal BMI status at age of 25 years. The proportion of women with live births " 1 or more" was a little higher among controls (87.34\%) versus cases $(84.81 \%)$. The proportion of women with the history of breast cancer in female relatives (mother) was slightly higher among cases (83.54\%) compared to controls (79.75\%). More women with $\mathrm{PBC}$ reported that they "ever used the hormonal therapy" among cases (92.41\%) versus controls (56.96\%). The summary of demographic and baseline characteristics is presented in Table 1 .

4.2. Weight Fluctuation. All 158 women self-reported weight assessments at age 25 and had three or more weight assessments before postmenopausal breast cancer diagnosis/end of 
TABLE 1: Demographics and baseline characteristics.

\begin{tabular}{|c|c|c|}
\hline Characteristics & $\begin{array}{c}\text { Cases } \\
N=79\end{array}$ & $\begin{array}{c}\text { Controls } \\
N=79\end{array}$ \\
\hline \multicolumn{3}{|c|}{ Age of diagnosis/years of follow-up $n(\%)$} \\
\hline $50-60$ & & \\
\hline $61-70$ & & \\
\hline $71-80$ & & \\
\hline 80 and above & & \\
\hline Mean (standard deviation) & & \\
\hline Minimum-maximum & & \\
\hline \multicolumn{3}{|l|}{ BMI at age 25} \\
\hline Mean (standard deviation) & & \\
\hline Minimum-maximum & & \\
\hline \multicolumn{3}{|l|}{ BMI status at age 25} \\
\hline Underweight & & \\
\hline Normal & & \\
\hline Overweight & & \\
\hline Obese & & \\
\hline \multicolumn{3}{|l|}{ Live births } \\
\hline 0 & $12(15.19 \%)$ & $10(12.66 \%)$ \\
\hline 1 or more & $67(84.81 \%)$ & $69(87.34 \%)$ \\
\hline \multicolumn{3}{|l|}{ Age $>30$ for birth of first child } \\
\hline Yes (1) & $4(5.06 \%)$ & $4(5.06 \%)$ \\
\hline No $(2)$ & $64(81.01 \%)$ & $68(86.08 \%)$ \\
\hline $\mathrm{N} / \mathrm{A}$ & $11(13.92 \%)$ & $7(8.86 \%)$ \\
\hline \multicolumn{3}{|c|}{ History of BC female relatives (mother) } \\
\hline Yes & $13(16.46 \%)$ & $16(20.25 \%)$ \\
\hline No & $66(83.54 \%)$ & $63(79.75 \%)$ \\
\hline \multicolumn{3}{|c|}{ Have ever used hormone therapy (HRT) } \\
\hline Yes & $6(7.59 \%)$ & $34(43.04 \%)$ \\
\hline No & $73(92.41 \%)$ & $45(56.96 \%)$ \\
\hline
\end{tabular}

follow-up (for controls). For cases, three weight assessments before cancer were collected for eight women (10.13\%) while the majority of cases $(88.61 \%)$ had five or more weight assessments. All controls (100\%) reported five or more weight assessments for the period of follow-up. The weight fluctuation was measured as root-mean-square-error statistic from simple linear regression of dependent BMI from independent age. It was higher in cases with mean (standard deviation) that is equal to $1.51(0.89)$ compared to controls 1.37 (0.86).

The assumptions underlying the regression models were checked with diagnostics statistics and plots. $R$-squares were considered acceptable. $R$-squares for controls were at the minimum of $50 \%$. There were two cases with $R$-square less than $2 \%$, and sensitivity analysis was conducted excluding these cases along with matched controls from the logistic regression models and did not change the results and conclusions (data is not presented).

4.3. Weight Gainers. It is known that weight gain is a risk factor for postmenopausal breast cancer [2-4]; however, most women who try to lose weight fail to maintain lost weight and gain weight even more [5-15]. The objective of the study was to investigate if weight fluctuation among weight gainers is an independent risk factor for PBC. Only weight gainers were chosen for this study where weight gain was defined as a positive slope $\left(\beta_{\mathrm{age}}\right.$-coefficient $\left.>0\right)$ from a simple linear regression of dependent variable BMI by independent age. In other words, weight gainers were women who had positive (or upward) trend in the weight change from age 25 through the adult years and to the last assessment before postmenopausal cancer diagnosis. On average, the last weight assessment was performed at about age of 60 years (standard deviation = 10.14) and was on average 2.7 (standard deviation $=2.28$ ) years before PBC diagnosis. Due to small sample size, the investigation of pre- or postmenopausal weight gain was out of scope in this study, as well as estimation of the different levels of weight gain.

4.4. Weight Fluctuation and Postmenopausal Breast Cancer. The odds ratio estimate for weight fluctuation from conditional logistic regression adjusted for weight gain ( $\beta_{\text {age }}$-coefficient/slope of BMI regression on age) was 1.674 
TABLE 2: The association between weight fluctuation and postmenopausal breast cancer.

\begin{tabular}{|c|c|c|c|c|}
\hline Model & Odds ratio & \multicolumn{2}{|c|}{ 95\% Wald confidence limits } & $p$ value (Wald Chi-square) \\
\hline \# 1: weight fluctuation (RMSE) & 1.674 & 1.056 & 2.655 & $0.0285^{*}$ \\
\hline \# 2: weight fluctuation (RMSE) & 2.917 & 1.385 & 6.142 & $0.0048^{*}$ \\
\hline
\end{tabular}

Model \#1 included weight gain.

Model $\# 2$ included weight gain, parity, first child at $>30$ years of age, history of cancer (mother), and have ever used hormonal therapy.

${ }^{*}$ The result is significant with $\alpha=0.05$.

(95\% confidence limit interval: 1.06-2.66) which means that each unit increase in weight fluctuation will increase the odds of getting PBC (versus odds of not getting PBC) by $67.4 \%$ among women who gain weight from age 25 .

The results from conditional logistic regression adjusted for parity, first child after 30 years of age, use of hormonal therapy, history of mother's breast cancer, and weight gain ( $\beta_{\text {age }}$-coefficient/slope of BMI regression on age) made association stronger with odds ratio for weight fluctuation as 2.92 (95\% CLI: 1.39-6.14). The results are presented in Table 2.

\section{Discussion}

The major finding of this study is that weight fluctuation during gaining weight in adult years is an independent risk factor for postmenopausal breast cancer.

National Task Force on the Prevention and Treatment of Obesity summarized the forty-three (43) English-language articles that evaluated the effects of weight fluctuation/cycling on humans or animals done from 1966 through 1994 [37]. The authors concluded that most studies demonstrated the association between body weight fluctuation and mortality and morbidity [37]. Nevertheless, it was hard to compare the results and drive solid conclusions because of the lack of standardized definition of weight fluctuation/cycling [37]. Search in PubMed for "weight cycling" and "cancer" revealed 21 articles with 14 related to the topic of cancer, while only three considered weight cycling as a risk factor for postmenopausal breast cancer. The conclusions of those studies are controversial. The review of those studies is summarized in Table 3.

French et al. investigated the association of weight variability and incidence of diseases including breast cancer [29]. It was the first study where weight variability was included as a separate category of weight changes during adulthood, and breast cancer in older women (55-69 years of age) was one of the outcomes under interest [29]. The authors used a sample of women from Iowa Women's Health Study (IWHS) who responded to the questionnaires and self-reported weight at ages 18, 39, 40, and 50 and current age [29]. Weight variability was defined in two ways. One way (RMSE analysis) was by the root-mean-square-error (RMSE) deviation around the linear slope of self-reported body weight at ages 18, 30, 40, and 50 [29]. And another way was by categories of the body weight changes between reported intervals of age [29]. The relative risk (RR) of breast cancer in relation to the quartiles of weight variability during adulthood (measured by RMSE) adjusted for slope of weight on age, baseline $\mathrm{BMI}, \mathrm{BMI}^{2}$, age, waist/hip ratio, smoking status (never, former, and current), pack years of cigarettes, education (<high school, high school, and $>$ high school), physical activity (low, medium, and high), alcohol ( $0,<4$, and $\geq 4 \mathrm{~g} / \mathrm{d})$, marital status (yes/no), and hormone replacement (never, former, and current) did not demonstrate the association with PBC: RR (95\% confidence limit interval) equals 1.05 (0.85-1.30), 0.89 (0.71-1.11), and $0.88(0.70-1.12)$ for $2 \mathrm{nd}$, 3rd, and 4th quartile, respectively (reference: 1st quartile of RMSE) [29]. In a second way, weight fluctuation was defined by the following categories of body weight changes derived from any two adjacent ages 18, 39, 40, and 50 and current age: large cycle (at least one gain $\geq 10 \%$ and at least one loss $\geq 10 \%$ ) or small cycle (includes at least one gain $\geq 5 \%$ but $<10 \%$ and at least one loss $\geq 5 \%$ but $<10 \%$ ) [29]. The reference category was a combined group of stable weight ( $<5 \%$ change between ages 18 and $62 \mathrm{y}$ ) and small gain (at least one gain between 5 and 10\%) [29]. Large gain category included at least one gain $\geq 10 \%$; and weight loss maintenance group included a $>10 \%$ weight loss with $\pm 5 \%$ maintenance of reduced value. The Others included all other unspecified weight change patterns [29]. The relative risks for weight changes categories adjusted for age, waist/hip ratio, BMI, $\mathrm{BMI}^{2}$, smoking status, pack years of cigarettes, education, physical activity, alcohol, marital status, and hormone replacement demonstrated that only large gain was statistically significant risk for incidence of breast cancer RR (95\% CI) $=1.29$ (1.02-1.63) [29]. Large cycle, small cycle, and weight loss and maintenance were not associated with increased risk of postmenopausal breast cancer with RR (95\% CI) being 0.83 (0.60-1.14), $0.86(0.58-1.27)$, and $0.81(0.50-1.30)$, respectively [29].

In 2000, Trentham-Dietz et al. conducted a large casecontrol study of postmenopausal women to investigate the risk of breast cancer associated with different patterns of weight changes [30]. The cases were women aged 50-79 years diagnosed with invasive breast cancer in states of Massachusetts, New Hampshire, and Wisconsin $(n=5031)$ and controls $(n=5255)$ were randomly selected from driver's license files and Medicare beneficiary lists [30]. All information for height, weight, and other breast cancer risk factors was collected through the telephone interviews conducted from July 1992 through July 1995 [30]. The conditional logistic regression on age and state was used to estimate odds ratios with 95\% confidence limit intervals adjusted for parity, age at first full-term pregnancy, family history of breast cancer, recent alcohol consumption, education, and age at menopause [30]. Weight cycling was defined as losing 20 or more pounds with the history of regaining at least half of it within a year [30]. The fact of weight cycling was self-reported by $18.6 \%$ among cases and $17.0 \%$ among controls [30]. Weight 


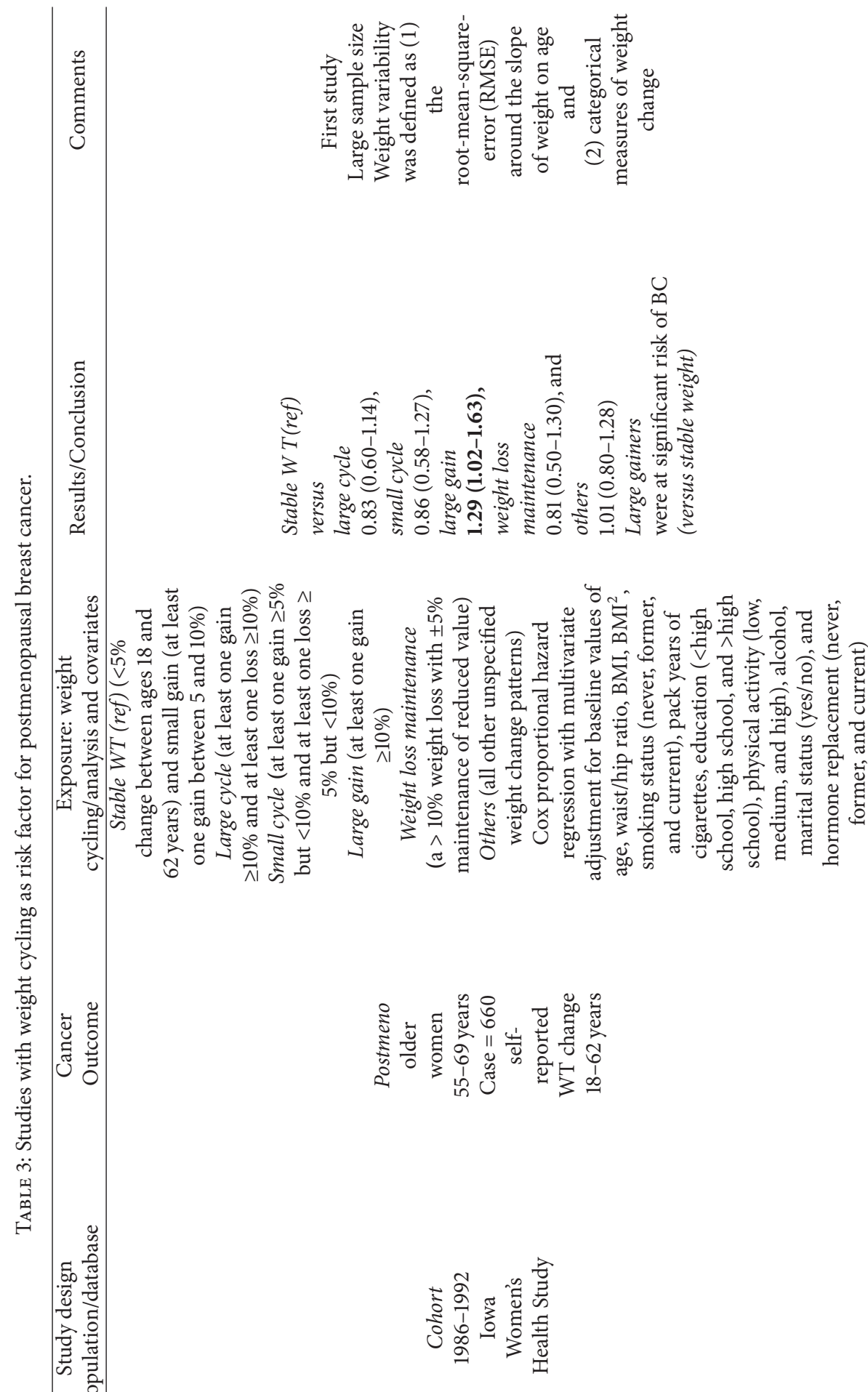

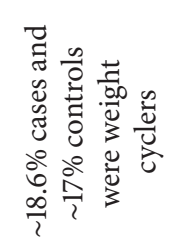

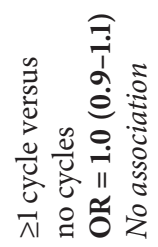

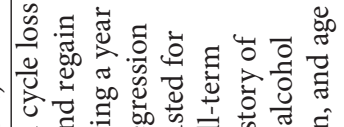

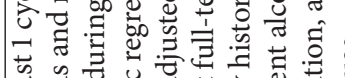

要

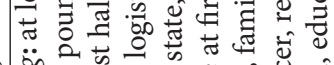

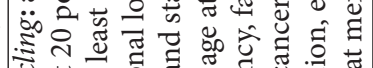

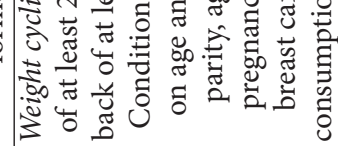

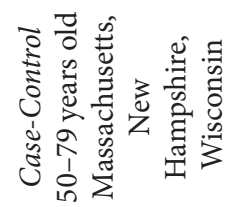

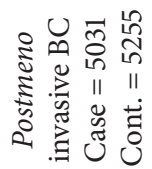

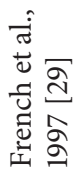

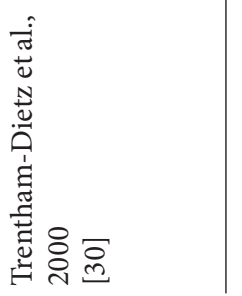




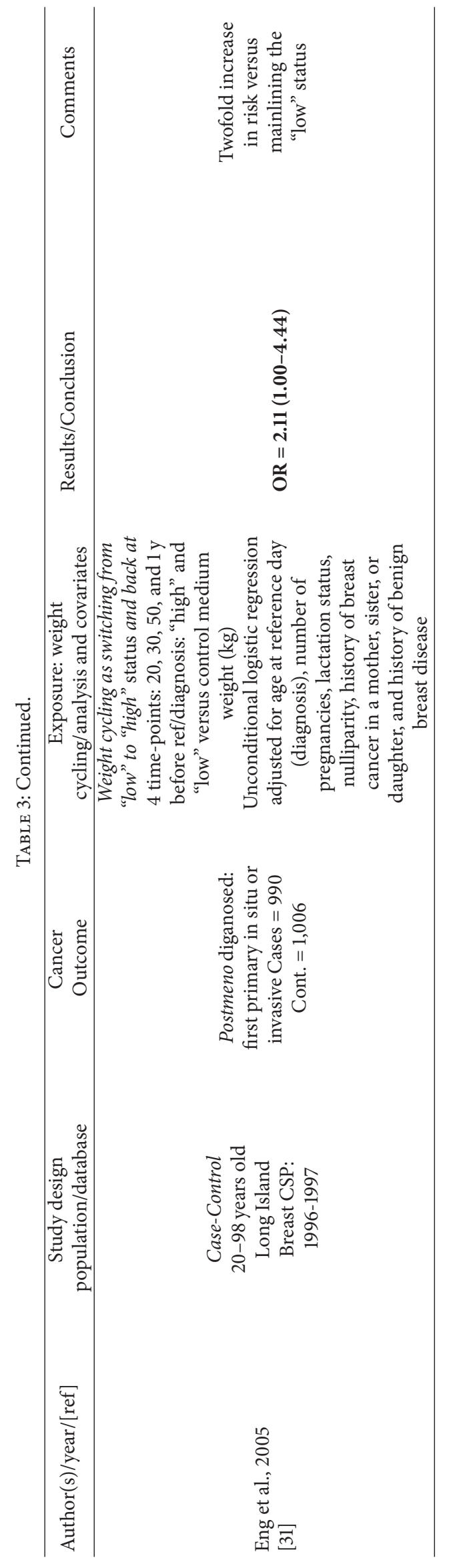


cyclers did not demonstrate the association with $\mathrm{PBC}$ relative to women who did not report any cycles $(\mathrm{OR}=1.0,95 \% \mathrm{CI}$ : 0.9-1.1) [30].

In 2005, Eng et al. conducted a population-based casecontrol study using participants in the Long Island Breast Cancer Study Project (LIBCP: 1996-1997) to investigate the effects of patterns of body size change throughout the lifetime on postmenopausal breast cancer risk [31]. Eng et al. underscored that their study was the second that explored effect of weight fluctuation (cycling) on risk of breast cancer [31]. The authors compared weight to the control median at four time-points: 20,30, 50, and 1 year before diagnosis (reference) where each subject was flagged "low" or "high" status below or above the control median [31]. The patterns of weight changes through life were defined as switching from "highlow" to "low-high" status or fluctuating [31]. Those groups were compared to the reference group defined as stable weight when the weight was consistently below the control median [31]. The patterns of "high-low" status consistently demonstrated the decreasing (not statistically significant) effect on risk of breast cancer, while those of "low-high" status were consistently opposite [31]. The weight cycling group demonstrated increase in risk of breast cancer with OR $(95 \% \mathrm{CI})=$ $2.11(1.00-4.44)$ [31].

The weight fluctuation/cycling were defined differently in three studies of postmenopausal women. The authors acknowledged that estimation of the risk of weight cycling is the hard task because of gaps in weight assessments in existing databases with long-term follow-up and lack of unified definition of weight cycling.

This study defines weight fluctuation similar to French et al. [29], but it is the first study with the goal of estimating the risk of weight fluctuation during adulthood among weight gainers. The rationale is that weight fluctuation provides a distinct effect on adipose tissue during weight regains and additional gains [11-15], working as an independent risk factor for PBC.

\section{Strengths and Limitations}

This is a novel study to investigate the effect of weight fluctuation during adulthood weight gain on PBC. The major strength of this study is use of national database. The major limitation is relatively small number of PBC cases. In addition, the majority of weight assessments were self-reported that introduced a recall bias (especially for 25, 40, and 65 years of age). Further studies are needed to confirm the results.

\section{Conclusion}

Understanding the relationship between weight fluctuation and postmenopausal breast cancer is very important. Many women go through weight loss programs to reduce weight gain. Yet, unsuccessful weight losses lead to weight regains and additional weight gain. This study demonstrated that weight fluctuation during weight gain is an independent risk factor for postmenopausal breast cancer. In summary, this project is one step forward to the goal of reducing the risk and the incidence of the disease. It will help to set up clear directions in weight control/management programs where successful interventions may improve health of many women.

\section{Conflict of Interests}

The author declares that there is no conflict of interests regarding the publication of this paper.

\section{Acknowledgments}

The author thanks Drs. Michael Szarek, Michael Walsh, and Elizabeth Helzner for assistance with development of this proposal.

\section{References}

[1] American Cancer Society, Cancer Facts and Figures, 2013, American Cancer Society, 2013.

[2] World Cancer Research Fund and American Institute for Cancer Research, Policy and Action for Cancer Prevention. Food, Nutrition, Physical Activity, and the Prevention of Cancer: A Global Perspective, AICR, Washington, DC, USA, 2007.

[3] World Cancer Research Fund/American Institute for Cancer Research. Policy and Action for Cancer Prevention, Food, Nutrition, Physical Activity, and the Prevention of Cancer: A Global Perspective-Final Summary, AICR, Washington, DC, USA, 2009.

[4] C. Eheman, S. J. Henley, R. Ballard-Barbash et al., "Annual report to the Nation on the status of cancer, 1975-2008, featuring cancers associated with excess weight and lack of sufficient physical activity," Cancer, vol. 118, no. 9, pp. 2338-2366, 2012.

[5] D. F. Williamson, M. K. Serdula, R. F. Anda, A. Levy, and T. Byers, "Weight loss attempts in adults: goals, duration, and rate of weight loss," American Journal of Public Health, vol. 82, no. 9, pp. 1251-1257, 1992.

[6] M. G. Stephenson, A. S. Levy, N. L. Sass, and W. E. McGarvey, "1985 NHIS findings: nutrition knowledge and baseline data for the weight-loss objectives," Public Health Reports, vol. 102, no. 1, pp. 61-67, 1987.

[7] J. Kruger, D. A. Galuska, M. K. Serdula, and D. A. Jones, "Attempting to lose weight: specific practices among U.S. adults," American Journal of Preventive Medicine, vol. 26, no. 5, pp. 402-406, 2004.

[8] S. B. Votruba, S. Blanc, and D. A. Schoeller, "Pattern and cost of weight gain in previously obese women," American Journal of Physiology-Endocrinology and Metabolism, vol. 282, no. 4, pp. E923-E930, 2002.

[9] A. E. Field, R. R. Wing, J. E. Manson, D. L. Spiegelman, and W. C. Willett, "Relationship of a large weight loss to long-term weight change among young and middle-aged US women," International Journal of Obesity and Related Metabolic Disorders, vol. 25, no. 8, pp. 1113-1121, 2001.

[10] S. Sarlio-Lähteenkorva, A. Rissanen, and J. Kaprio, "A descriptive study of weight loss maintenance: 6 and 15 year follow-up of initially overweight adults," International Journal of Obesity, vol. 24, no. 1, pp. 116-125, 2000.

[11] R. W. Jeffery, M. T. McGuire, and S. A. French, "Prevalence and correlates of large weight gains and losses," International Journal of Obesity and Related Metabolic Disorders, vol. 26, no. 7, pp. 969-972, 2002. 
[12] A. E. Field, J. E. Manson, C. B. Taylor, W. C. Willett, and G. A. Colditz, "Association of weight change, weight control practices, and weight cycling among women in the Nurses' Health Study II," International Journal of Obesity, vol. 28, no. 9, pp. 1134-1142, 2004.

[13] E. Cereda, A. E. Malavazos, R. Caccialanza, M. Rondanelli, G. Fatati, and M. Barichella, "Weight cycling is associated with body weight excess and abdominal fat accumulation: a crosssectional study," Clinical Nutrition, vol. 30, no. 6, pp. 718-723, 2011.

[14] I. Strychar, M.-É. Lavoie, L. Messier et al., "Anthropometric, metabolic, psychosocial, and dietary characteristics of overweight/obese postmenopausal women with a history of weight cycling: a MONET (Montreal Ottawa New Emerging Team) study," Journal of the American Dietetic Association, vol. 109, no. 4, pp. 718-724, 2009.

[15] S. J. Wallner, N. Luschnigg, W. J. Schnedl et al., "Body fat distribution of overweight females with a history of weight cycling," International Journal of Obesity, vol. 28, no. 9, pp. 1143-1148, 2004.

[16] American Cancer Society, Cancer Facts and Figures 2012, American Cancer Society, 2012.

[17] American Cancer Society, Cancer Facts and Figures 2011, American Cancer Society, Atlanta, Ga, USA, 2011.

[18] American Cancer Society, Cancer Facts and Figures 2010, American Cancer Society Inc, 2010.

[19] U.S. Department of Health and Human Services and National Institutes of Health, Weight Cycling, U.S. Department of Health and Human Services, National Institutes of Health, 2008.

[20] P. S. MacLean, J. A. Higgins, M. R. Jackman et al., "Peripheral metabolic responses to prolonged weight reduction that promote rapid, efficient regain in obesity-prone rats," American Journal of Physiology-Regulatory Integrative and Comparative Physiology, vol. 290, no. 6, pp. R1577-R1588, 2006.

[21] P. S. MacLean, J. A. Higgins, G. C. Johnson et al., "Enhanced metabolic efficiency contributes to weight regain after weight loss in obesity-prone rats," American Journal of PhysiologyRegulatory Integrative and Comparative Physiology, vol. 287, no. 6, pp. R1306-R1315, 2004.

[22] P. S. MacLean, J. A. Higgins, G. C. Johnson, B. K. Fleming-Elder, J. C. Peters, and J. O. Hill, "Metabolic adjustments with the development, treatment, and recurrence of obesity in obesityprone rats," American Journal of Physiology-Regulatory Integrative and Comparative Physiology, vol. 287, no. 2, pp. R288R297, 2004.

[23] E. E. Kershaw and J. S. Flier, "Adipose tissue as an endocrine organ," The Journal of Clinical Endocrinology \& Metabolism, vol. 89, no. 6, pp. 2548-2556, 2004.

[24] S. Galic, J. S. Oakhill, and G. R. Steinberg, "Adipose tissue as an endocrine organ," Molecular and Cellular Endocrinology, vol. 316, no. 2, pp. 129-139, 2010.

[25] M.-H. Wu, Y.-C. Chou, W.-Y. Chou et al., "Circulating levels of leptin, adiposity and breast cancer risk," British Journal of Cancer, vol. 100, no. 4, pp. 578-582, 2009.

[26] C.-A. Sun, M.-H. Wu, C.-H. Chu et al., "Adipocytokine resistin and breast cancer risk," Breast Cancer Research and Treatment, vol. 123, no. 3, pp. 869-876, 2010.

[27] E. E. Calle, "Adiposity and cancer," in Adipose Tissue and Adipokines in Health and Disease, Nutrition and Health, pp. 307-325, Humana Press, New York, NY, USA, 2007.
[28] International Agency for Research on Cancer, Weight Control and Physical Activity, vol. 6, International Agency for Research on Cancer, Lyon, France, 2002.

[29] S. A. French, A. R. Folsom, R. W. Jeffery, W. Zheng, P. J. Mink, and J. E. Baxter, "Weight variability and incident disease in older women: the Iowa women's health study," International Journal of Obesity, vol. 21, no. 3, pp. 217-223, 1997.

[30] A. Trentham-Dietz, P. A. Newcomb, K. M. Egan et al., "Weight change and risk of postmenopausal breast cancer (United States)," Cancer Causes and Control, vol. 11, no. 6, pp. 533-542, 2000.

[31] S. M. Eng, M. D. Gammon, M. B. Terry et al., "Body size changes in relation to postmenopausal breast cancer among women on Long Island, New York," American Journal of Epidemiology, vol. 162, no. 3, pp. 229-237, 2005.

[32] National Center for Health Statistics, "NHANES data sets and related documentation," http://www.cdc.gov/nchs/about/major/ nhanes/datalink.htm.

[33] C. S. Cox, M. E. Mussolino, S. T. Rothwell et al., "Plan and operation of the NHANES I Epidemiologic Followup Study 1992," National Center for Health Statistics. Vital Health State, vol. 1, no. 35, 1997.

[34] B. B. Cohen, Plan and Operation of the NHANES I Epidemiologic Followup Study, 1982-84, United States Department of Health and Human Services, USPHS, National Center for Health Statistics, Hyattsville, Md, USA, 1987.

[35] J. T. Massey, T. F. Moore, V. L. Parsons, and W. Tadrros, Design and Estimation for the National Health Interview Survey, 198594, vol. 119 of Vital and Health Statistics, Series 2, National Center for Health Statistics, Hyattsville, Md, USA, United States Department of Health and Human Services Publ. no. 89-1384 (USPHS), 1985.

[36] E. L. Korn and B. I. Graubard, "Epidemiologic studies utilizing surveys: accounting for the sampling design," American Journal of Public Health, vol. 81, no. 9, pp. 1166-1173, 1991.

[37] "Weight cycling. National task force on the prevention and treatment of obesity," JAMA: The Journal of the American Medical Association, vol. 272, no. 15, pp. 1196-1202, 1994. 


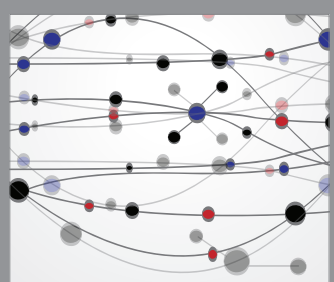

The Scientific World Journal
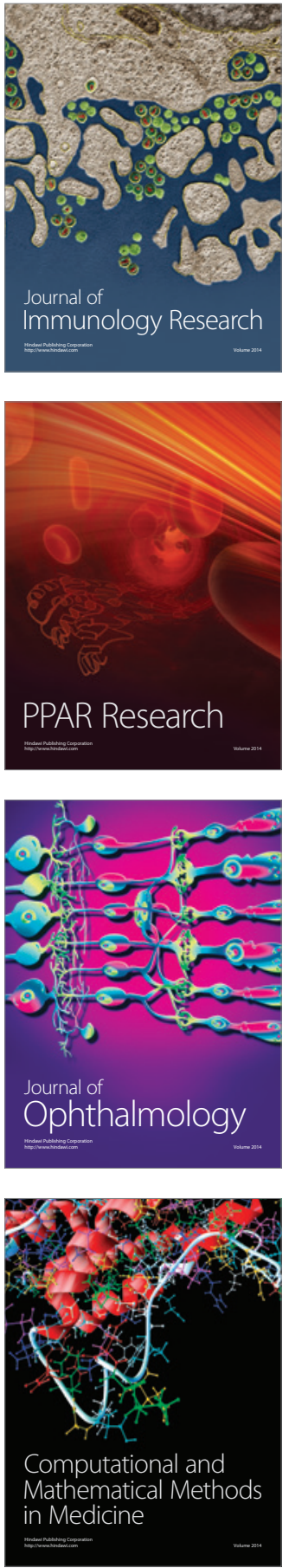

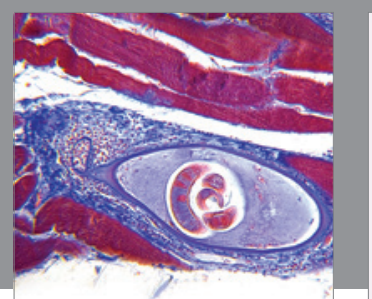

Gastroenterology Research and Practice

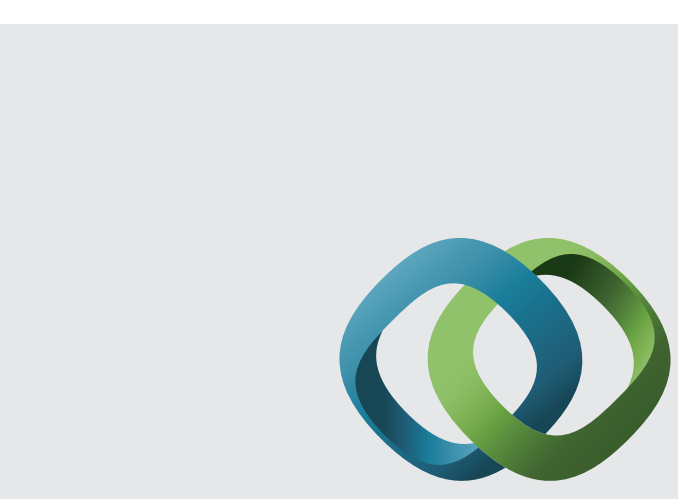

\section{Hindawi}

Submit your manuscripts at

http://www.hindawi.com
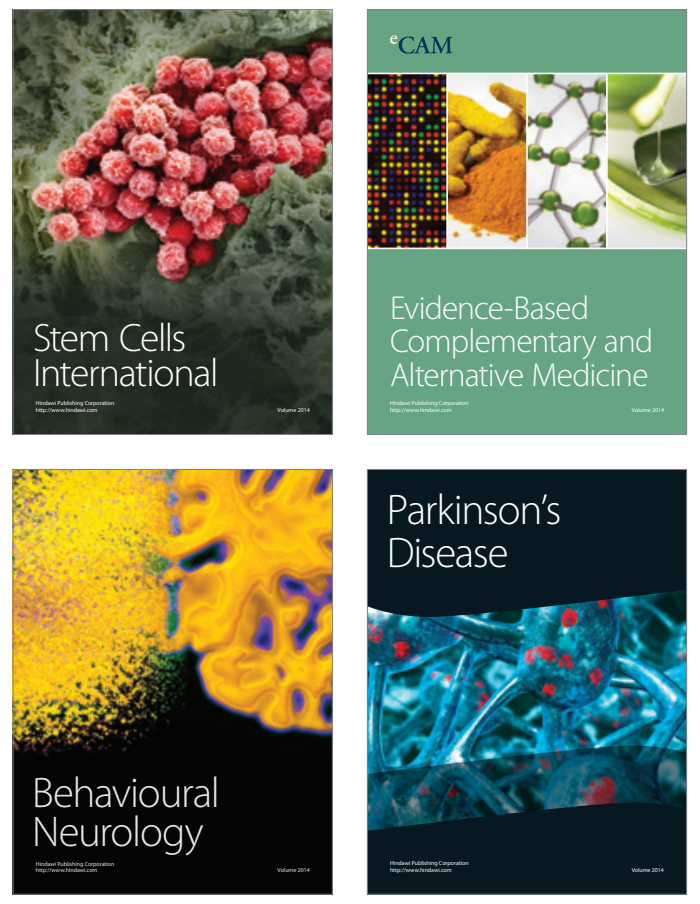
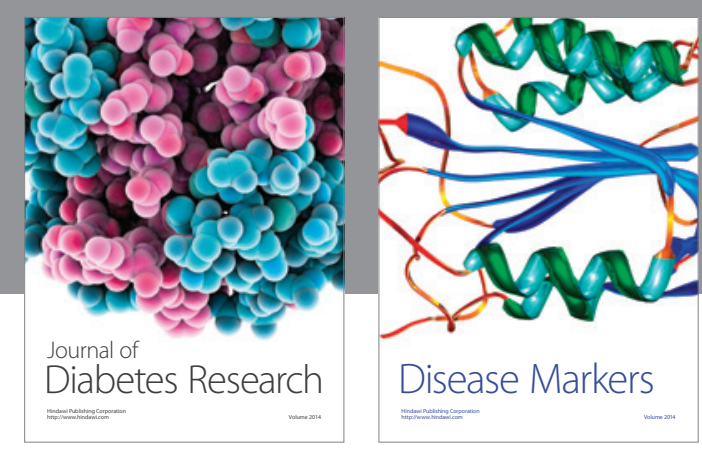

Disease Markers
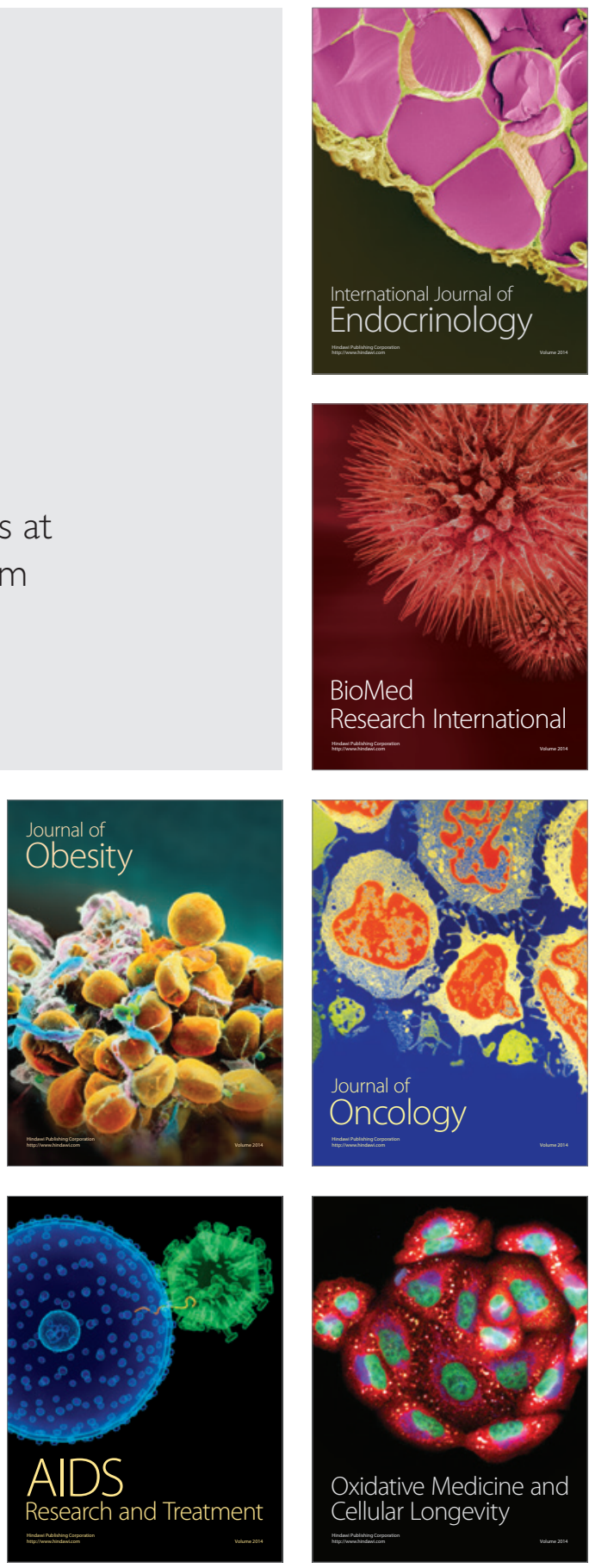